\title{
Devolution of Power: Impact Assessment on Primary Education
}

\author{
Aijaz Ahmed Mahesar and Dr. Mustaghis-ur-Rahman \\ SZABIST \\ Karachi, Pakistan
}

\begin{abstract}
Devolution of power in Pakistan had been awaited since long. The old colonial system of governing from the top had failed to deliver and the services at local level had been deteriorating. There was a general feeling that the incapacity of the system to respond to the development needs is due to non-participation of the local community in the decision-making. Education amongst the other services had been affected badly since the inception of the country despite several attempts to formulate, review and implement newer policies at various intervals. It has been hoped that the service delivery will improve with the promulgation of Local Government Ordinance (LGO) 2001, which for the first time introduced a shift of paradigm to manage local government system with active participation of the community. The aim of this study is to explore whether the new governance model has made any positive impact on primary education, which now rests with the local governments. The research for the study is exploratory cum descriptive and qualitative in nature. The primary data has been collected in the field through discussions and interviews of the stakeholders on a pre-set questionnaire. Mostly, the data is qualitative in nature. However, the author has tried to analyze the data through descriptive statistical methods. Pie charts and bar charts have been applied for data interpretation to arrive at the result of the study.
\end{abstract}

Keywords: Devolution of power, local government, primary education, school management committees, education sector reforms

\section{INTRODUCTION}

'Devolution of power' in Pakistan saw the dawn of the day on $14^{\text {th }}$ August 2001 with the promulgation of Local Government Ordinances in all the four provinces of Pakistan. Its need was felt since long and it had been on the cards for decades. It was vigorously pursued by agents of change in view of the prevalent system being out-dated, obsolete, and unfriendly and too centralized [1]. The old system of administration lacked democracy and accountability at the local level. Governance was centralized so that decisions about local level planning and development were taken at the higher level, with little reference to local needs and priorities. Because civil servants were not answerable to the public, there was little incentive for them to ensure high quality service delivery. Lack of checks and balances left the system open to abuse. The Local LGO brought about a wholesale transformation in Pakistan's system of government, especially at the local level. Divisions were abolished, and at their place a threetier local government structure comprising of three categories of local government-districts has been introduced. In the existing system, the civil servants are accountable to the elected representatives, who are in turn accountable to the public at the local level. Devolution in Pakistan follows the principle whereby all functions that can be effectively performed at the local level are transferred to that level. This has meant the decentralization to the districts and Tehsils of many functions previously handled by the provincial governments. Section 14, Chapter III of SLGO, 2001 under its title "Decentralized offices and grouping of offices" declares that "on the commencement of this Ordinance, the administrative and financial authority for the management of the offices of the government specified in Part-A of the First Schedule, set up in a district shall stand decentralized to the District Government of that district [2]. Alongside administrative and political decentralization, provisions have been made for transfer of funds to the local governments so that they can carry out their planning and development functions effectively. These funds are made available to the local governments through Provincial Finance Commission, a forum established under Section 120-A [2] for determining and affecting the Fiscal Transfers to the Local Governments.

Amongst the services, which are now to be taken care of at the 3rd tier, is, 'Education'. Education plays a vital role in the development of a nation in terms of its social, cultural and economic growth, which leads to the general satisfactory conditions for the inhabitants of a given society or a country. It is generally believed that a good quality education plays a key role in the economic and social development of a country by improving the quality of human capital, that in turn engage in the planning and development process. Unfortunately, Pakistan's educational standards do not portray a satisfactory picture till date. The illiteracy rate is high; gross and net enrolment is low; there are wide gender and regional disparities in the opportunities to acquire education; dropout rates are high; and quality of educational service is poor [3]. How far the devolved system of education has been able to address the problems with the education system is the focus of this study.

\section{LITERATURE REVIEW}

Education is a process of living through a continuous reconstruction of experiences. Such continuous reconstruction of experiences has witnessed disturbing trends in the sub-continent throughout the known history. From the vernacular to foreign mediums of learning, it has gone a long way to reach to the point at this moment in 
history, where we find it to be still unsure which path suits it well. Pakistan inherited British model of formal education at its inception, which had over-written the vernacular system of education being practiced since centuries. However, to accept it as our role model, we thought to contemplate the issues involved in the system as a whole and look out for the best alternates. Pakistan Educational Conference, an advisory body, was asked by the Government of Nascent State to suggest proposals for the improvement in the Education Sector and assisting the Education Division in late 1947 [4]. Quaid-e-Azam, Muhammad Ali Jinnah in his message to the Conference said: "There is no doubt that the future of our State will and must greatly depend upon the type of education we give our children, and the way in which we bring them up as future citizens of Pakistan". However, the quest to rationalize our education system and conform it to our needs seems to have been abandoned in spirit soon after. With no adequate funding and planning, education as an institution kept on sailing like a ship without rudder. The Education System, however, has passed through several phases of change. A total of 8 known major state policies were conceived and undertaken by the government [5]. Devolution of the education to the district governments is the latest change in the governance, aimed at involving the community in the management of schools and ensuring the quality education.

It is imperative to mention here that, half of the world's illiterate and 22 percent of the world's population live in South Asia [6]. Pakistan, if compared to its regional countries, does not fare well on account of literacy. Sri Lanka and Maldives have almost attained full literacy. The adult literacy rate for India is 61 as compared to 53 percent in Pakistan. India, according to a recent study done by the World Bank, has attained 100 percent Gross Enrollment Ratio (GER) and 90 percent Net Enrollment Ratio (NER) at the primary level [7]. Given the situation, it is much important to track the performance of the devolved education service in order to foresee whether the intervention is on the track.

\section{EDUCATION POLICIES INTRODUCED BY THE GOVERNMENT SINCE ITS INCEPTION}

After the independence of Pakistan, the Education System passed through several phases of change.

As many as eight major attempts were made to revamp the system of education prevalent in Pakistan to make it more responsive to the needs of the hour and enable it to provide the grounds for the sustainable development in the country [5] which broadly are:

1) Pakistan Education Conference, 1947

2) Commission on National Education, 1959

3) New Education Policy, 1970

4) Education Policy, 1972

5) National Education Policy, 1979

6) National Education Policy, 1992

7) National Education Policy, 1998-2010
8) Education Sector Reforms, Strategic Plan 20012004

It is interesting to note that; the effect of all these reforms pushed the cause of education backwards and brought in more confusions than it resolved. The graph of learning and developing a critical approach amongst the students dipped down with each attempt to pull it up. General perception amongst the educationists today is that a matriculate of 50s was more knowledgeable, wise and analytical than the graduate of 90s. Above all, the falling standards of societal values, observable through the naked eye, with the passage of time stand to the testimony of the falling standards of education in the country. There is, therefore, a point to ponder that if the institute of education fails to create a sense of awareness amongst the people to govern their respective and collective life, it is failing in its delivery.

\subsection{Devolution Plan 2001}

Was it the failure of the policies or the system of administering the education, which lay behind its failure, is a debatable question? Policies might be somewhat general directions to move forward in improving the standards; however, it's the administration of the system and efforts to ensure service delivery, which makes the real difference. This vision got translated into reality through the promulgation of LGOs in all the four provinces of Pakistan, which has been so far the major change of governance model since the inception of the country. Prior to the promulgation of SLGO 2001, the education from Primary to the Intermediate level was administered by the Provincial Department of Education through its attached offices in the erstwhile Divisional Headquarters and field offices in the districts and Talukas of the province. Under the new system, the administration as well as management has been decentralized to the district governments along with the finances to run the system. As far as the case of education is concerned, a unique principle of governance was introduced which required the mandatory involvement of the local community in the running as well as monitoring and evaluating of the education service in the form of School Management Committees (SMCs). Such a management intervention was in the backdrop of the perception that moving away from centralized control is an obvious precondition to expanding equitable access to education, a key objective of the decentralization.

SMCs have been made fairly independent and empowered to run the schools and carry out the developmental activities through their funds, which are provided through the budgetary allocations by the government. SMCs are also authorized to raise their own revenue through community mobilization.

Complementing to the aim of improving the education system, approximately 6 months to the promulgation of LGOs, President Pervez Musharraf's government presented its Education Sector Reform (ESR) plan in 
January 2002. ESR aimed at modernizing the education system, a yet another policy intervention in addition to the administrative reforms affected through LGOs. A major objective of the ESR is to develop a more secular system in order to offset mounting international scrutiny and pressure to curb religious extremism in the wake of the $11^{\text {th }}$ September, 2001 attacks. The National Plan of Action for Education for All was initiated in response to the commitment made at Dakar for World Summit. The Education Reform Action Plan (ESR), which is built upon the National Education Policy 1998-2010, is a long-term plan, with three yearly action plans. The ESR addresses the development of the overall education sector through investment in rehabilitation of schools, improving the curriculum and assessment reform system, an adult literacy campaign, mainstreaming the Madrassas, a pilot school nutrition program and technical stream in secondary schools. The Poverty Reduction Strategy Paper (PRSP) views education as a strong policy instrument in bringing poverty down [8].

\section{DATA COLLECTION AND INTERPRETATION}

The primary data for the purpose of the study is collected from the field, across the 21 primary schools of the target population, as per following methodology:

\section{4(a) Data collection}

A detailed questionnaire was developed to seek the data from the field to assess the impact of the devolution on the education system. It was addressed to four groups of stakeholders involved in the education system, which are:

1. Head teachers of the primary schools of Matiari district

2. District education officers

3. Chairman and members of the School Management Committees

4. Parents of the students enrolled in the primary schools under survey

Some of the indicators to assess the impact of the new governance model were to see:

a) Whether the enrolment has increased in the post decentralization period?

b) Whether the number of teachers has increased in the post decentralization period?

c) Have more classrooms been added?

d) Whether the basic facilities have been provided where lacking?

In all, 21 broad questions were set for the four groups, mostly of which were addressed to Group "a” because of its being focal in the education system. A total of 11 questions were formed for this group which were discussed in detail, after seeking proper time from them, in order to get the realist input from the stakeholders. It is reiterated here that the research methodology employed in the study is exploratory cum descriptive and qualitative in nature.

There are 932 primary schools in the entire district, which constituted the universe of the population for the purpose of the study. The target population of the survey was those schools whose enrolment was 100 and above, which was 216 schools. $10 \%$ of those schools were surveyed during the field visits.

The data collected on the above-referred indicators has been shown in the charts on the following page: 
Table 1: Enrolment status of Matiari

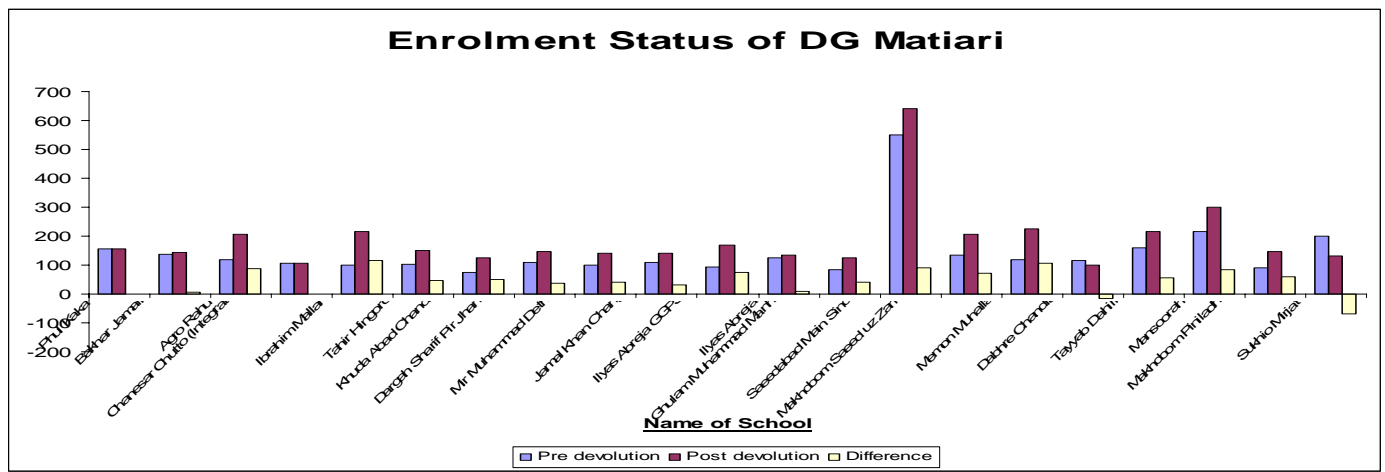

Table 2: Number of teachers posted in schools

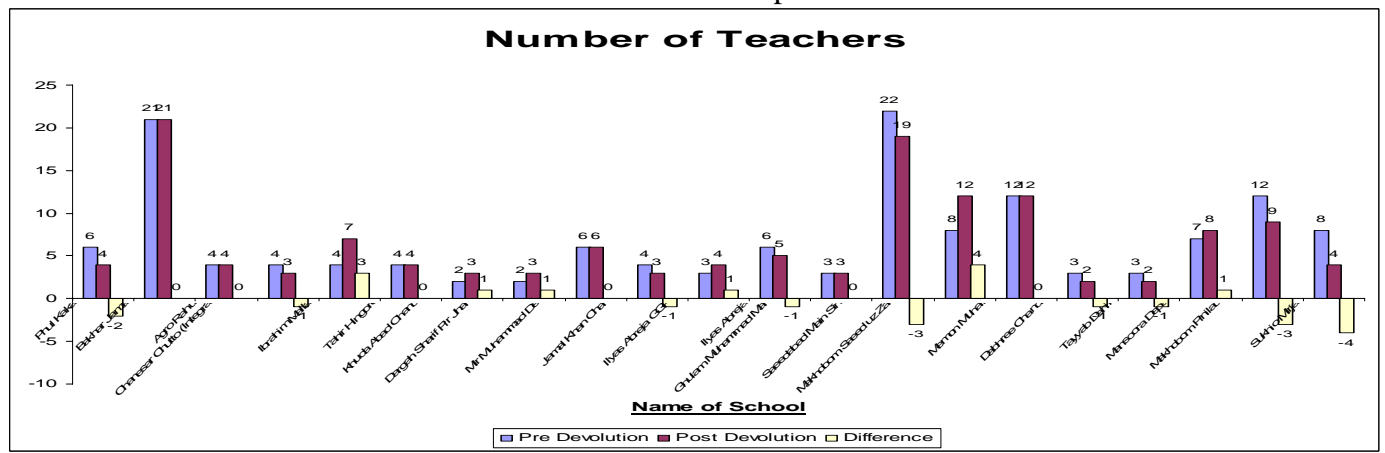

Table 3: Number of classrooms

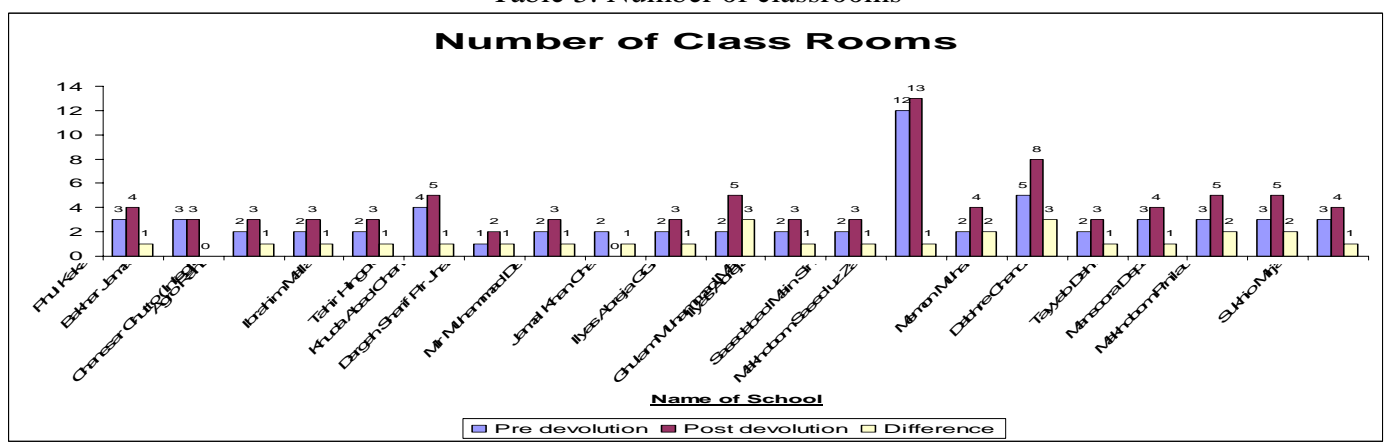

Table 4: Provision of electricity and drinking water

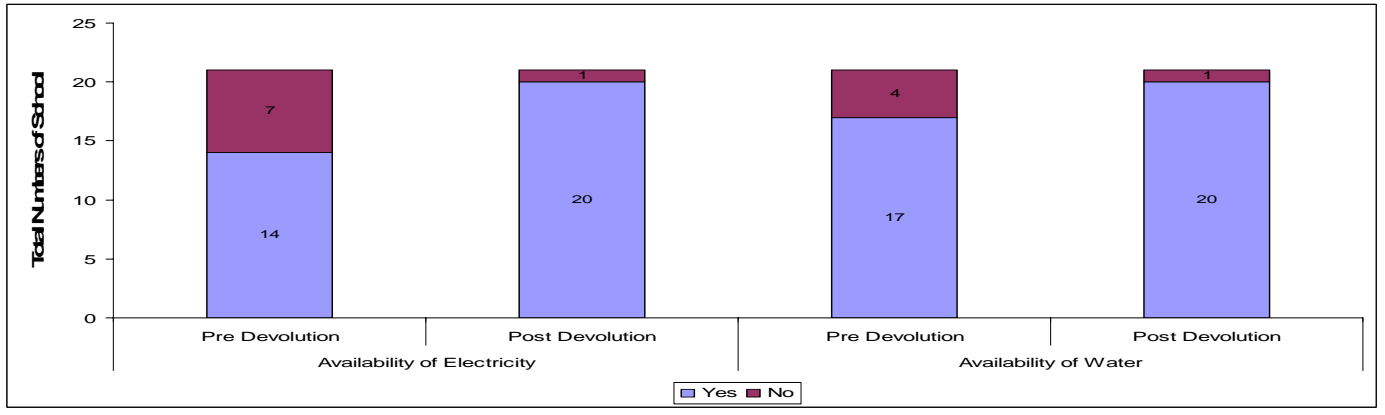




\section{4(b) Data interpretation}

The data pertaining to the various indicators on the pre and post devolution scenario, as reflected in the above tables, is interpreted and analyzed in the following paragraphs:

(i) Enrolment analysis of Matiari:

Analysis of the figures (Table 1) reveal that only two schools out of 21 surveyed schools in the district surveyed have shown negative trend in raising the enrolment level in their respective schools in the post decentralization scenario. Rest of 19 schools saw a robust rate of increase in the enrolment, confirming the official statistics of the high growth in the rate of enrolment, which according to SEMIS Draft Report 2006 is 82 percent [9]. General increase in the total enrolment in the surveyed schools is found to be 27.3 percent over and above the enrolment base existing in the pre-decentralization period, as ascertained in the primary survey conducted by the author.

(ii) Number of teachers posted in the schools: Post decentralization has witnessed a disturbing scenario in so far as the student per teacher ratio is concerned (Table 2). The general increase in the enrolment in the corresponding period has increased at an average of 27.3 percent, while at the same time the number of teachers for the same schools has reduced to $4.1 \%$. Individual analysis of the teachers working in the surveyed primary schools reveal that 9 out of 21 schools have reduced the number of teachers; 5 have made no change; while only 6 schools showed an increase in teachers as compared to the predecentralization period. Student per teacher ratio in the pre-decentralization period was 21, while in the post decentralization period it has increased to 28. With the enrolment on increase, it would be appreciated if there is a corresponding increase in the number of teachers as well in the schools in order to sustain the demands that generate due to the increase in enrolment.

(iii) The state of infrastructure development:

Over all development activities in the surveyed schools have been positive (Table 3). Barring only one school, the rest of 20 schools have constructed one or more classrooms in the post decentralization period. The increase in the developmental activities is robust 44 percent, showing the positive fund flow in the post devolution scenario.

(iv) Status of the basic facilities in the schools:

The availability of electricity and drinking water in the schools has also improved in the post decentralization period (Table 4). Previously, 9 out of 21 schools were without the provision of electricity, while now, there remains only 1 school (Dabhree Chandia), which is without the provision of electricity. Similarly, there were 4 schools, which were without the basic facility of drinking water in the pre-decentralization period. There remains only one school now, which has yet to get the facility.

\section{4(c) School Management Committees}

One shift of paradigm in the process of decentralization in Pakistan is formation of the School Management Committees (SMCs) [10]. In all, 832 SMCs have been formed in these schools, as per the SEMIS record, signifying $89 \%$ coverage of the total schools in the district that run under the new system and with active community participation through these Committees. However, the primary data collected through meeting the district officers revealed that about $70 \%$ to $75 \%$ of SMCs have actually been formed and the number quoted by the district officers was 750 instead of 832.

\section{RESULTS AND FINDINGS}

i. Findings of the study have revealed that the impact of decentralization of primary education has been positive so far. Enrolment of the students in primary schools has increased in the post decentralization scenario in the entire district as analyzed from the sample survey of schools. The role of SMCs in raising the enrolment is found to be very positive. It is very interesting to find out that almost all the Head Teachers and the District Education Officers have attributed the increase in enrolment to the community participation in the management of schools, a tribute to the concept of SMCs.

ii. It is again interesting to note that despite all the credit to SMCs for their positive input in increasing the enrolment, they have not been properly trained in discharging their duties. Members of only two of the SMCs, out of 21 surveyed by the author, informed to have been trained in their roles and responsibilities by Donor Agencies (ESRA/US Aid in this case) working in the area, while the rest of them have yet to get any such training. Without the formal attempt to train these Committees on the part of the government, the efforts put in by the SMCs and the results thereof seem to be commendable which can be further improved upon if they are consciously trained on their roles and responsibilities as part of the capacity building of the provincial education department. Although, most of them are generally aware about their responsibility to liaise with the district administration to resolve management issues and also to supervise the attendance of both teachers 
and students as well as keep an eye on the enrolment of students, they have yet to work on their other as much important responsibilities like: help improve academic performance, review and provide for the co-curricular activities, generate funds to make the institute self sufficient, and most importantly to prepare annual development plan for the institution. These responsibilities assigned to SMCs are pivotal for the sustainable education and institution building.

iii. One of the alarming situations in the post decentralization scenario is that, the total number of teachers working in the schools has reduced as compared to the immediate pre-decentralization period, as evident from the primary figures collected from the field. Reduction in staff can, in no manner, be assigned to the decentralization process as the recruitment is still with the provincial education department.

iv. Infrastructure development has also witnessed a positive change. Barring one, all schools under survey had added one or more classrooms to their building. There used to be no direct funding to the schools in the pre-decentralization period while they have it now, which is operated through SMCs. Direct funding to the schools may be one cause of positive trend in the infrastructure development. However, there was a uniform demand of the Head Teachers and members of SMCs to make the SMCs thoroughly independent and more powerful, than it is now. Some of the powers of the SMCs, like planning for the development activities of their respective schools, postings and transfers of the teachers and other staff, are eroded through the political interference that patronizes the services of certain individuals for one reason or other. Political interference, in this regard, is found to be endemic in so far the transfer/postings of the teachers and other staff of the schools is concerned. Chairmen of SMCs complained of a tough ride when it comes to stopping transfer of a teacher by the district administration, which is more amenable to oblige the politicians than to the SMCs.

v. Another positive development in the post decentralization scenario is the increasing availability of the basic necessities like provision of electricity and drinking water in the schools, which again has been attributed to the positive efforts of the SMCs.

vi. The general feeling of the stakeholders is positive about the new system of administration. Only one of the Head Teachers out of 21 interviewed, during the survey, was apprehensive of the efficiency of the new system and a few of district education officers viewed it to be a "change which is merely on the paper", rest of them; however, appreciated the working of the new system and called for strengthening the same. A general complaint of the Head Teachers and members of SMCs was the lack of support from the district administration in resolution of the school issues as and when they crop up. Although the field staff has been relieved of traveling long distances in connection with the official work, there still seems to be an unreal gap between the officers responsible for catering to the needs of the educational requirements and the staff who actually are providing the services in the field.

vii. Parents of the children enrolled in schools were found to be satisfied with the kind of education being provided generally and were aware of the efforts being put in by the SMCs to improve the condition of schools as well as service delivery. Most of the parents referred to the interest of their children to go to school regularly to be an indicator that the school environment improved.

\section{CONCLUSION}

Finding of the study has revealed that the impact of decentralization of primary education system to the district government's level has been positive. Enrolment of the students in the primary schools has increased in the post decentralization scenario. The role of SMCs in raising the enrolment is found to be very positive. However, one of the alarming situations in the post decentralization scenario is that the total number of teachers working in the schools has reduced as compared to the immediate predecentralization period. Infrastructure development has witnessed a positive change. Barring one, all schools under survey had added one or more classrooms to their building. Another positive development in the post decentralization scenario is the increasing availability of the basic necessities, such as provision of electricity and drinking water in the schools. Parents of the children enrolled in schools were found to be satisfied. Most of the parents referred to the interest of their children to go to school regularly to be an indicator that the school environment has improved. The results reveal that the latest intervention of the government to improve the performance of primary education has started giving positive results; however, at the same they are at stake, given the irresolute and half hearted attitude of higher management in allowing the devolved administration to work as per the mandate assigned to them. Community participation has discouraged the element of ghost schools to crop up anew. The schools are open to the maximum number of days as compared to past. Education offices are being equipped with computers, improving the management systems. Creation of the post of District Officer (SEMIS) has resulted in much improved and reliable school census data, which is expected to become a 
dynamic database on which the decision-making is expected to be fairly organized, scientific and efficient.

However, there still remain some grey areas, which require attention of the policy makers. The local political influence in frequent transfers and postings of the teachers has resulted in 2 categories of schools; i.e. schools with heavy deployment of teachers and schools with fewer teachers than required. A much harmful tendency in the new system is that the development projects are more focused on the ruling party affiliated areas, which is against the equitable distribution of resources. Yet another issue is failure to address the need to hire additional teachers, which is slowly leading to disaster in view of the increasing trend of enrolment. Furthermore, capacity building of the School Management Committees is not being addressed institutionally. If the SMCs are left to work purely on their own wisdom and without the institutional effort to train them on a standardized way of working, their contribution may not be as much fruitful as is desired.

\section{RECOMMENDATIONS}

- $\quad$ Any new change in the system has to be steered through out till that change brings in the satisfactory results and institutionalizes the desired intervention. Devolution of education to the district level seems to be a positive change, which requires to be monitored by the higher authorities on regular basis. The issues, which crop up due to conflict of interests amongst the various stakeholders in the new reality can only be addressed when the change is being monitored constantly. This important strategy to implement the devolution plan seems to be missing. Even then, the change has started giving positive results already.

- Although the teachers employed in the primary education sector seem to be highly qualified and trained, yet, their performance in imparting the quality education seems to be far from satisfactory.

- A comprehensive policy to induct the deserving candidates as teachers on the sole basis of merit along with guidelines for their transfer and postings, ensuring their posting to the most convenient places and incentive based remuneration, has yet to see the light of the day.

- $\quad$ Besides that, there seems to be no monitoring and evaluation framework to oversee the functioning of SMCs, which requires to be framed.

\section{REFERENCES}

[1] Finance Division, Decentralization Support Program: A New System of Government, Government of Pakistan http://www.decentralization.org.pk/whatisdsp.asp
[2] The Sindh Local Government Ordinance, Government of Sindh, page 114, 2001.

[3] The State of Pakistan Economy, First Quarterly Report FY06, State Bank of Pakistan, page 81 http://www.sbp.org.pk/reports/quarterly/FY06/first/Sp cial_Section.pdf

[4] Dr. Baloch, N.A. A National System of Education and Education of Teachers, Sindhica Institute of Policy Studies, Larkana, pages 18, 165, 2003.

[5] Personal interview with Dr. Baloch, N.A Ex-Minister of Education, Government of Sindh and former Vice Chancellor, University of Sindh.

[6] Mehboobul Haq, Human Development Report, Human Development Centre, Islamabad, 2003.

[7] "Poverty Reduction Strategy Paper", Government of Pakistan, Finance Division, Islamabad, page 160, 2006

http://www.finance.gov.pk/survey/sur_chap_05-6/11education.PDF

[8] Economic Survey of Pakistan, Government of Pakistan, Islamabad, Chapter 11, Page 159, 2005-06.

[9] District Profiles, SEMIS Draft Report, Govt. of Sindh, Education Department, Chapter 23, Page 2, 2006.

[10]Aao Mil Kar School Ssanwarein - booklet on the Roles and Responsibilities of the SMCs, Indus Resource Centre Education and Literacy Department, Govt. of Sindh. 